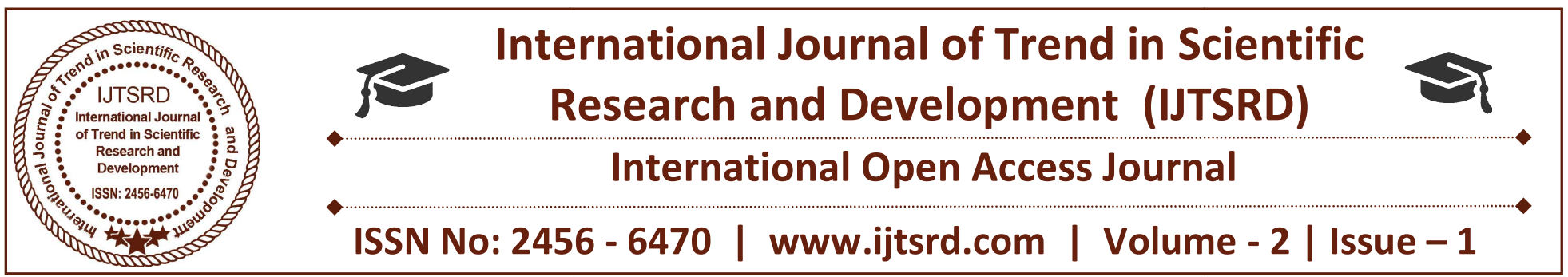

\title{
Wollastonite: An Energy Efficient Building Material
}

Vikrram Singh Meena

Centre for Energy and Environment, Malaviya

National Institute of Technology, Jaipur, India

\author{
Deven Singh \\ Department of Civil Engineering, Career Point \\ University, Kota, India
}

\begin{abstract}
Cement production is synonymous to green house emissions and mineral resource depletion. So as to produce about 1 tonne of cement, 1.5 tonne lime stone is required and nearly 1tonne green house gases are emitted out. This article present sustainable use of calcium meta silicate mineral "wollastonite" (CaSio3) as a partial replacement of cement. Six concrete mixes were prepared by replacing cement with wollastonite $(0-25 \%)$. Test result showed that $10 \%$ wollastonite can effectively replace cement with improvement in strength and durability parameters. Incorporation of wollastonite in cement production will help in sustainable development of country.
\end{abstract}

Keywords: Wollastonite, Green Building, Permeability, Carbonation, Durability

\section{INTRODUCTION}

The estimated cement production in India was 233 million metric tonnes for the year 2012 with an annual growth rate of $8.6 \%$. To produce a huge quantity of cement, naturally occurring materials such as limestone, chalk, clay are mined and processed every year. As we know cement is highly energy-intensive material, due to the dominant use of carbon intensive fuels, e.g. coal, in clinker making. The increased energy cost in the recent years has been reflected in correspondingly higher cost of cement.

The production of cement depletes natural resources and also conventional concrete does not last for long. Properties of concrete can be modified by the use of mineral admixtures, commonly used as an addition to
Portland cement concrete mixtures to increase the long term properties and in some cases to reduce the material cost of concrete. Several materials including fly ash, silica fume, metakaolin, slag, wollastonite etc. which are either industrial wastes or naturally occurring minerals, have been investigated by researchers for improving concrete properties.

Wollastonite is a calcium meta-silicate mineral. Extensive deposits (56 million tonne) of wollastonite are located in Pali, Sirohi and Udaipur districts of Rajasthan, India. Wollastonite is a low cost material with its extensive deposits in USA, Canada, Australia, China and India. The objective of present investigation is to determine the influence of wollastonite on the strength, permeability and carbonation properties of concrete. 7, 28, 90 days Strength, Water permeabilityat 28 days and carbonation at 42 days have been evaluated over 0.38 water-binder $(\mathrm{w} / \mathrm{b})$ ratio and cement replacement percentages between 0 to $25 \%$.

\section{BACKGROUND LITERATURE}

Compressive strength was observed decreasing at each $\mathrm{w} / \mathrm{b}$ ratio, while the flexural strength was observed increasing between 7.5 and $15 \%$ cement replacement by wollastonite at $\mathrm{w} / \mathrm{b}$ ratios $(0.475$, 0.55 ) and decreasing at $0.40 \mathrm{w} / \mathrm{b}$ ratio [1]. Higher cement replacement up to $50 \%$ by wollastonite resulted in decreasing compressive, flexural strength and marginal variations in pull-off strength with increase in cement replacement by wollastonite [2]. 
Cement was replaced by wollastonite-fly ash combination (50:50) up to 50\%. Each strength parameter was observed decreasing with increase in wollastonite content [3]. Mathur et al. observed reduced water absorption of concrete mixes containing wollastonite and fly ash [4]. In another study, five concrete mixes including mix without any cement replacement. Wollastonite with and without microsilica was used as partial replacement of cement, saturated water absorption, rate of water absorption, coefficient of water absorption were observed. It was found that incorporation of wollastonite $(15 \%)$ and microsilica $(7.5 \%)$ in the concrete significantly improves water tightness due to reduction in pore space and refinement of micro structure [5]. Reduced water absorption and initial surface absorption was observed with increase in wollastonite content [1]. Misra et al. [2] in their study on concrete mixes with cement replacement by wollastonite up to $50 \%$ observed that the protective quality as per the ISAT and air permeability index (Pressure/min) results at each replacement level of cement by wollastonite and at each w/b ratio was good indicating enhancement in cover zone properties. It was observed that the rate of initial surface absorption decreases with increase in wollastonite-fly ash (W-FA) content in concrete mixes [3] The $\mathrm{w} / \mathrm{b}$ ratio mainly affects the rate of concrete carbonation, because improvement in the pore structure is mainly governed by this [9], [10]. Investigations on durability aspects of concrete containing wollastonite and other mineral admixtures are currently underway in Concrete Technology Lab., MNIT, Jaipur.

\section{EXPERIMENTAL PROGRAMME}

For the present investigations Portland cement, coarse and fine aggregates were procured locally and wollastonite (Kemolit $\mathrm{H}-3 \mathrm{~K}$ ) was procured from Wolkem India Ltd, Udaipur (Rajasthan).Potable water as per IS-456 along with Supoflo (Don Construction Chemicals India Ltd.) super plasticizer conforming to ASTM type-F was used for this study.

Physical properties of the materials used (cement, wollastonite, and aggregates) were examined first. Physical properties viz. particle size, specific gravity, crushing strength, impact value, flakiness and elongation index and free surface moisture content were tested. All materials were found confirming to relevant specifications. The experimental program was conducted at $\mathrm{w} / \mathrm{b}$ ratio of 0.38 prepared by partial replacement of cement by equal weight of wollastonite. Each set had mixes at four different percentages of cement replacement. The dosages of wollastonite were $0,5,10,15,20$ and $25 \%$ of the total cementitious materials; The dosages of plasticizer in concrete mixes used were between 0.15 and $1 \%$ for each water cement ratio. All sample preparations were processed in a similar manner. Wollastonite was gradually blended with concrete until a uniform mix was obtained. The mixing procedure and time were kept constant for all the concrete mixes investigated. Compacting factor test was conducted to find the workability of different concrete mixes.

The concrete mixture was allowed to harden at ambient temperature for 24 hours. After casting the hardened concrete cubes were then de-moulded. After the de-moulding process, the specimen blocks were kept for hydration for a period of 7, 28 and 90 days. The methods followed were standard procedures, carbonation (CPC-18 RILEM), and permeability (DIN 1048). Each result is reported as the average value of three specimens tested. The experimental programme was outlined in such a way that variation of the attributes such as consistence, strength, permeability and carbonation of wollastonite added concrete composite, with respect to the quantity of cement replaced by wollastonite could be examined.The water permeability test set up was used to measure the permeability. Concrete specimens were exposed to a water pressure of $0.5 \mathrm{~N} / \mathrm{mm}^{2}$ acting normal to the mould-filling direction, for a period of three days. This pressure was kept constant throughout the test. Immediately after the pressure has been released, the specimen was removed and split down from the centre, with the face which was exposed to water facing down. Then the maximum depth of water penetration was measured and the extent of water penetration established.

For carbonation studies, cube specimens for each mix were prepared. After 28 days of curing, they were stored in a proper way. Then, each cube was divided in to four pieces having $50 \mathrm{~mm}$ width and $100 \mathrm{~mm}$ length and these pieces (12 pieces for each mix) were kept in oven at $60-70^{\circ} \mathrm{C}$ for two weeks. Fully oven dried samples were then coated with two coats of epoxy paint around the longitudinal sides. After coating, drying and marking the samples, they were kept in carbonation chamber with controlled relative humidity (50-65\%), Carbon dioxide concentration $5 \pm 0.2 \%$ and temperature $27 \pm 2^{\circ} \mathrm{C}$ were kept controlled. Observations were taken on 3 pieces from each mix at an interval of 14, 21, 28 and 35 days. The specimens 
were further broken into two halves and $\mathrm{pH}$ indicator was sprayed on broken face. A standard solution of $1 \%$ phenolphthalein in $70 \%$ ethyl alcohol was used. In the noncarbonated region with $\mathrm{pH}$ values above 9.2, the phenolphthalein indicator turns purple-red and in the carbonated portion with $\mathrm{pH}$ less than 9.2, the solution remains colourless. Comparison of control mix produced without cement replacement and mixes produced with cement replacement up to $25 \%$ was done. Each experimental result value was the average of three specimens.

\section{RESULTS AND DISCUSSION}

Basic properties of constituent materials concrete mixes were studied prior to investigate permeability and carbonation properties. Plasticizer was used between 0.15 and $1 \%$ to obtain a desired level of workability. With increase in cement replacement in concrete mixes workability reduces at each $\mathrm{w} / \mathrm{b}$ ratio. Workability of concrete containing wollastonite was observed degrading with increased wollastonite content. The high SSA of wollastonite in comparison to cement produced more internal friction with in the concrete and degrading its workability.

Compressive strength results at 7, 28 and $90 \mathrm{~d}$ (Figure 1) exhibited a similar trend. With the incorporation of wollastonite, strength decreased at each replacement level. The loss in strength can be attributed to lack of binding ability in wollastonite. The increasing replacement levels resulted in less amount of cement available to bind the concrete constituents. However, the reduction in strength for the mixes containing 5 and $10 \%$ wollastonite was small. The mixes containing 5 and $10 \%$ wollastonite achieved the target strength of $40 \mathrm{MPa}$ after $28 \mathrm{~d}$, indicating that concrete of desired strength can be obtained by replacing 10\% cement with wollastonite. Maximum strength was observed for sample R1 (43 MPa) and minimum for sample R6 (35.4 MPa) at $28 \mathrm{~d}$. Mixes containing 5 and $10 \%$ wollastonite, attained strength of $42.4 \mathrm{MPa}$ and $41.1 \mathrm{MPa}$ after $28 \mathrm{~d}$.

Results of water permeability test at 28 days as shown in Fig. 2, indicate decrease in permeability with increase in cement replacement by wollastonite upto $15 \%$. Results of carbonation test at 42 days as shown in Fig. 3 indicate decrease in carbonation depth with increase in cement replacement by wollastonite. Permeability and carbonation resistance are two important parameters which determine durability of concrete. These two factors are pre-dominantly responsible for corrosion of reinforcements in RCC. Permeability and carbonation properties are function of concrete matrix. Replacing cement by wollastonite (up to $15 \%$ ) densified the concrete matrix. There-by, enhancing its resistance to carbonation and permeation.

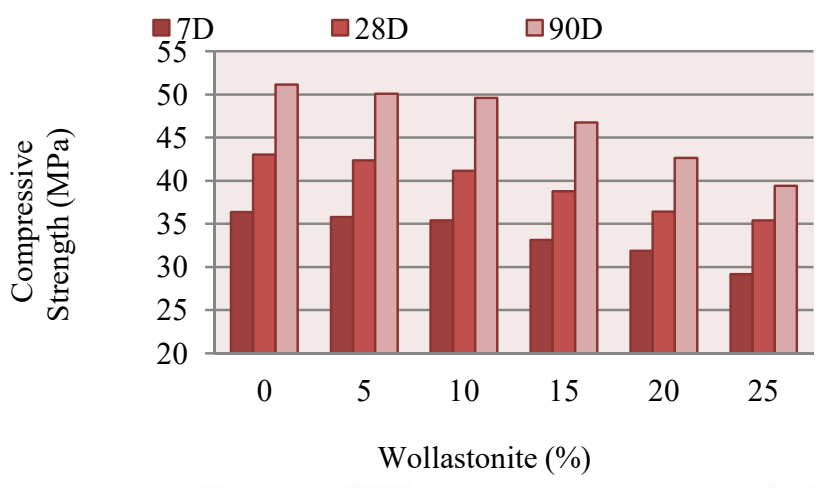

Figure-1 Wollastonite v/s 28 Compressive Strength

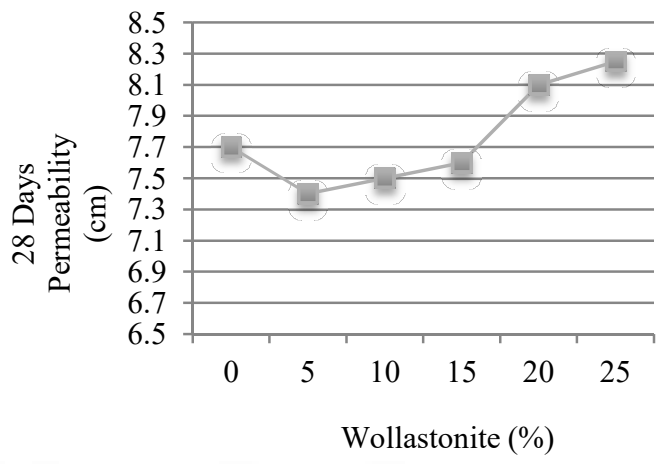

Figure-2 Wollastonitev/s 28 days water permeability

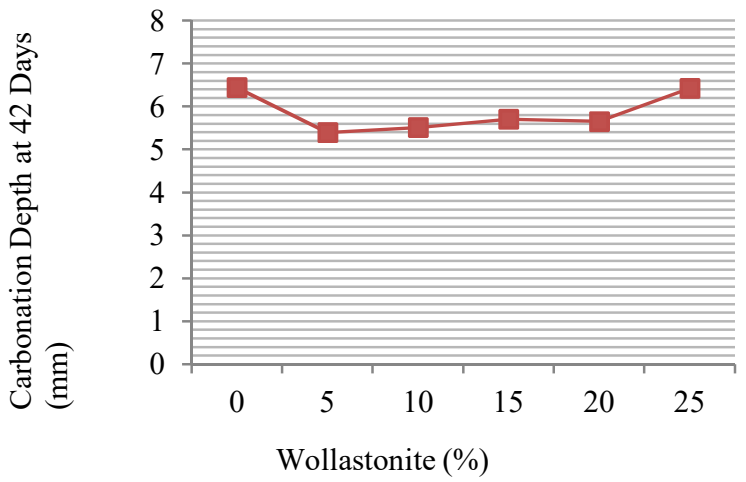

Figure-3: Wollastonitev/s 42 days carbonation depth

\section{CONCLUSIONS}

Test results indicated that wollastonite can efficiently substitute cement without affecting mechanical parameters of concrete. Replacing 10\% cement can 
even enhance the longevity of concrete structures. The gainful utilization of wollastonite as building material will contribute to sustainable development of country by reducing green house emissions and depletion of natural resources.

\section{REFERENCES}

1) A Misra.,C.B Mathur., P Kalla and G. S.Meena., "Strength and Absorption Studies on Concrete Containing Wollastonite," Indian Highways, Vol. 37 (3) , pp.33-38, 2009.

2) A Misra, A.N. Arora, P. Kalla and H. Panchal, "Strength, Absorption and Permeability Characteristics of Concrete Containing Wollastonite," Indian Concrete Institute, Vol. 12 (2), pp.17-22, 2011.

3) P.Kalla., A.Misra and G.Sancheti, "Properties of wollastonite and flyash added concrete," Indian Highways, Vol. 39 (12), pp.25-31, 2011.

4) R Mathur, A.K.Misra and P. Goel, "Marbel Slurry Dust and Wollastonite-Inert Mineral Admixtures for Cement Concrete," Indian Highways, Vol. 35 (12), pp.41-46, 2007.

5) G.D.Ransinchung, B.N Singh, B.Kumar and V.Kumar. "Microstructural Behaviour of Wollastonite And Microsilica Admixed Concrete For Rigid Pavements", Highway Research Journal, Vol. 1(1), pp. 13-20, 2008.

6) A.Oner, S.Akyuz. and R.Yildiz, "An Experimental Study on Strength Development of Concrete Containing Fly ash and Optimum Usage of Fly ash in concrete", Cement and Concrete Research, vol. 35,pp. 1165-1171 2005.

7) B. Kumar, G.K.Tike and P.K.Nanda, "Evaluation of Properties of High-Volume Fly ash Concrete for Pavements", Journal of Materials in Civil Engineering, ASCE,pp. 906-911,2007.

8) H.Sheng, B.Xu and T.Shi, "Determination of Gas permeability of High Performance Concrete Containing Fly ash", Material and structures, Vol. 41,pp. 1051-1056, 2008.

9) H.Khaiat and N.Fattuhi, "Carbonation of Concrete Exposed to Hot and Arid Climate", ASCE, journal of materials in civil engineering, pp. 97-107, 2002.

10) N.Fattuhi, "Carbonation of concrete as affected by mix constituents and initial water curing period", Material and Construction, Vol. 19 (110), pp. 131136, 2006.
11) P.Sulapha., S.Wong, T. Wee and S.Swaddiwudhipong, "Carbonation of Concrete Containing Mineral Admixtures", Journal of materials in civil engineering, pp. 134-143, 2003.

12) "Evaluation of Wollastonite in Concrete work", Central Road Research Institute, New Delhi, 2004.

13) B. L Rajput. And I Singh, "Green Concrete - An Overview”, Indian Highways, Vol. 40 (2), pp 4351, February 2012.

14) G.D.Ransinchung., B.Kumar and V.Kumar., "Assessment of Water Absorption and Chloride ion Penetration of Pavement Quality Concrete Admixed with Wollastonite and Microsilica", Construction and Building Materials, Vol. 23,pp. 1168-1177, 2009.

15) N.M.PLow and J.J Beaudoin, "Flexural strength and microstructure of cement binders reinforced with wollastonite micro-fibers", Cement Concrete Research, Vol. 23 (4), pp 905-916, 1993.

16) N.M.P Low and J.J Beaudoin, "The effect of wollastonite micro-fiber aspect ratio on reinforcement of Portland cement-based binders", Cement Concrete Research, Vol. 23,pp 14671479, 1993.

17) N.M.P Low and J.J Beaudoin, "Mechanical properties and microstructure of high alumina cement based binders reinforced with natural wollastonite micro-fibres", Cement Concrete Research, Vol. 24 (4), pp. 650-660, 1994.

\section{BIOGRAPHIES}

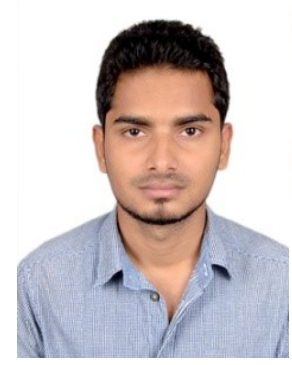

Vikrram Singh Meena

M.Tech- Renewable Energy Malaviya National Institute Of Technology, Jaipur, India B.Tech- Electrical Engineering Jamia Millia Islamia, New Delhi, India

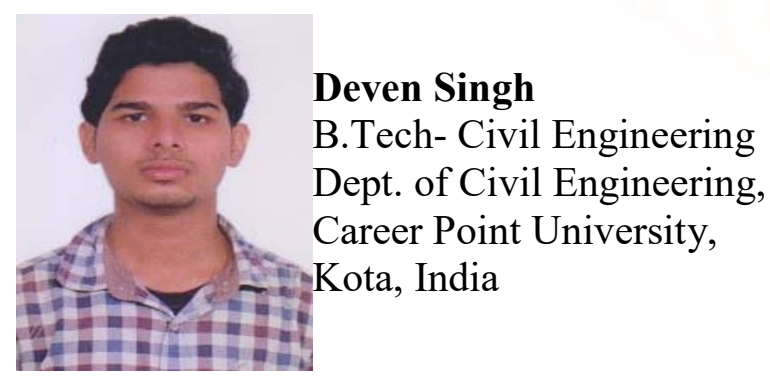

